\title{
Decisões reprodutivas e triagem neonatal: a perspectiva de mulheres cuidadoras de crianças com doença falciforme
}

\author{
Reproductive decisions and newborn screening: the perspective \\ of female caregivers of children with sickle cell disease
}

Cristiano Guedes ${ }^{1}$

${ }^{1}$ Universidade de Brasília. Caixa Postal 8011, Setor Sudoeste. 70673-970

Brasilia DF.

cguedes@unb.br

\begin{abstract}
One of the goals of the Brazilian Newborn Screening Program created in 2001 was to inform couples with the possibility of having children with sickle cell diseases regarding reproductive decision-making. This article presents the reproductive choices and analyzes the notion of biomedical reproductive risk of female caregivers of children with sickle cell disease participating in a newborn screening program. Qualitative data collected between 2006 and 2008 was based on interviews with 50 female caregivers of children with sickle cell disease participating on the Federal District Newborn Screening Program. The research revealed the following perceptions underlying reproductive decisions: women who want to have other children even with the risk of recurrence of the disease; women who do not want to have any more children; and women whose reproductive plans are still being considered on the basis of the information provided by the newborn screening program. The study revealed that women's reproductive choices are based on the experience of child care and self care. The notion of reproductive risk is built in order to strengthen women's decisions together with their family and other social groups to which they belong.
\end{abstract}

Key words Newborn screening, Reproductive decisions, Sickle cell disease, Genetics
Resumo Um dos objetivos do Programa Nacional de Triagem Neonatal para doença falciforme, criado em 2001, foi o de informar casais com chances de ter filhos com doenças falciformes para a tomada de decisões reprodutivas. Este artigo apresenta as escothas reprodutivas e analisa a noção de risco reprodutivo biomédico de mulheres cuidadoras de crianças com doença falciforme inseridas em um programa de triagem neonatal. O levantamento de dados qualitativos, realizado de 2006 a 2008, foi baseado em entrevistas com 50 mulheres cuidadoras de crianças com doença falciforme participantes do Programa de Triagem Neonatal do Distrito Federal. A pesquisa revelou as seguintes percepções no campo das decisões reprodutivas: mulheres que querem ter outros filhos mesmo sob o risco de recorrência da doença; mulheres que não querem mais ter filhos; $e$ mulheres cujo projeto reprodutivo ainda está sendo elaborado com base nas informações recebidas no programa de triagem. O estudo mostrou que as escolhas reprodutivas das mulheres são embasadas na experiência do cuidado dos filhos e de si. A noção de risco reprodutivo é construída de modo a fortalecer as decisões das mulheres perante a família e outros grupos sociais ao qual pertence.

Palavras-chave Triagem neonatal, Decisões reprodutivas, Doença falciforme, Mulheres, Genética 


\section{Introdução}

Uma das metas do Programa Nacional de Triagem Neonatal, criado em 2001, é a educação em saúde como estratégia de redução da morbimortalidade em razão das doenças triadas. O programa, que pode ser considerado uma referência na América Latina, fornece diagnóstico precoce, tratamento e medicamentos a todas as crianças identificadas com doenças ${ }^{1,2}$. Apesar dos avanços obtidos na primeira década de existência, o programa brasileiro apresenta alguns desafios a serem superados, tais como: a ausência de cobertura em todo o território nacional; a falta de estrutura em saúde capaz de assegurar o diagnóstico e o tratamento de todos os recém-nascidos; e a formação insuficiente de profissionais para o fornecimento de educação em saúde ${ }^{3-5}$. É por meio de práticas educativas em saúde, como aconselhamento genético, publicações ou palestras, que os programas de triagem neonatal sensibilizam as famílias para a importância do tratamento precoce, da adoção de cuidados em saúde das crianças, planejamento familiar e risco reprodutivo.

O termo "risco reprodutivo" é uma expressão utilizada na literatura biomédica para se referir a pessoas ou casais com chances de ter filhos com doenças genéticas, em virtude do genótipo que possuem ${ }^{6}$. Em sessões de aconselhamento genético, os profissionais de saúde da triagem neonatal informam o casal sobre as chances de terem filhos com doenças falciformes, bem como sobre as características das doenças, o patrimônio genético familiar, as possibilidades de recorrência ou de ocorrência da doença e os cuidados reprodutivos que podem ser adotados ${ }^{7-10}$. Os estudos sobre aspectos reprodutivos no campo da genética ainda são raros no Brasil, apesar da crescente importância epidemiológica dessas doenças que resulta do processo de transição epidemiológica observado na população.

No cenário internacional, também são pouco frequentes os estudos sobre reprodução no campo da genética e das doenças falciformes. A maioria dos estudos sobre percepção de risco reprodutivo tem como foco principal outros tipos de doenças genéticas, como câncer de mama e ovário, Doença de Huntington, fibrose cística e síndrome de Down ${ }^{11}$. As pesquisas internacionais revelam que as pessoas constroem a percepção de risco baseadas em uma combinação de fatores que envolve trajetória de vida pessoal e familiar, crenças culturais e individuais, contexto socioambiental, ocupação laboral, hábitos alimentares e especificidades genotípicas e fenotípi- cas das doenças ${ }^{11-15}$. Esta pesquisa elegeu como participantes mulheres cuidadoras de crianças com doença falciforme devido à sua elevada prevalência no Brasil e à centralidade dessas mulheres para o sucesso dos programas de triagem neonatal ${ }^{16-21}$.

Este artigo tem como objetivo analisar a percepção de risco reprodutivo e seus desdobramentos nas decisões reprodutivas de mulheres cuidadoras de crianças com doença falciforme no Distrito Federal.

\section{Metodologia}

Este artigo é resultado de uma pesquisa de Ciências da Saúde com abordagem qualitativa, voltada para mulheres usuárias do Sistema Único de Saúde (SUS) no Distrito Federal. As participantes da pesquisa foram mulheres, mães e cuidadoras de crianças diagnosticadas com doenças falciformes e identificadas pelo teste do pezinho. O Distrito Federal, embora não esteja cadastrado na Fase II do Programa Nacional de Triagem Neonatal, etapa que autoriza as unidades da Federação a realizarem triagem e posterior tratamento de crianças com doenças falciformes, possui um programa próprio que possibilita o diagnóstico precoce de recém-nascidos e o fornecimento de tratamento.

$\mathrm{Na}$ coleta de dados foi utilizada a técnica de entrevista por meio de um roteiro de perguntas semiestruturado. Essa técnica tem sido utilizada com êxito em outras pesquisas qualitativas cujos propósitos e objetos de estudo se assemelham ao deste trabalho, segundo evidencia a literatura científica especializada ${ }^{22-24}$. Trata-se de uma técnica que possibilita identificar o sentido dado pelas mulheres à experiência do diagnóstico precoce e compreender seus desdobramentos após a análise do conteúdo das entrevistas ${ }^{25}$. As entrevistas foram realizadas por uma mulher, no total de quarenta, ou por um homem, totalizando dez, ambos estudantes de pós graduação e assistentes sociais. Todas foram transcritas, submetidas a leitura minuciosa, seleção de trechos diretamente relacionados aos objetivos do estudo, microanálise dos dados presentes nos trechos selecionados e codificação dos resultados em três categorias apresentadas na seção de análise deste artigo $^{26}$.

Como critérios de inclusão para participar da pesquisa foram entrevistadas mulheres cujos filhos foram diagnosticados pelo teste do pezinho como portadores de doenças falciformes e posteriormente tiveram o diagnóstico confirmado por 
meio de novo teste. Por isso, as entrevistas ocorreram a partir dos primeiros quatro ou cinco meses de vida da criança, quando o diagnóstico estava confirmado e o tratamento fora iniciado. As entrevistas foram realizadas, preferencialmente, no domicílio das mulheres. No caso de mulheres não residentes no Distrito Federal ou aquelas cujo endereço era desconhecido/desatualizado, optou-se por realizar as entrevistas no hospital enquanto as mulheres aguardavam o atendimento ambulatorial periódico das crianças. Os convites para participar da pesquisa foram mediados por um hospital público, centro de referência para triagem neonatal e atendimento de crianças com doenças falciformes no Distrito Federal, por ocasião dos atendimentos fornecidos às crianças. $\mathrm{O}$ projeto de pesquisa foi submetido e aprovado pelo Comitê de Ética em Pesquisa da Secretaria de Estado da Saúde do Distrito Federal antes do período de coleta de dados.

Durante 18 meses, foram entrevistadas 50 mulheres. Estas foram escolhidas por conveniência e a quantidade de entrevistas levou em consideração a saturação da amostra. Todas as entrevistadas residiam em regiões da periferia ou do entorno do Distrito Federal. Para se ter uma ideia da dimensão da amostra - um grupo de 50 pessoas cuidadoras de crianças com doenças falciformes -, um levantamento realizado de 2004 a 2006 mostrou que no Distrito Federal haviam nascido 109 crianças portadoras de anemia falciforme, o que representa uma prevalência de 9 crianças com essa doença a cada 10 mil nascimentos ${ }^{18}$.

Sobre o perfil das participantes da pesquisa, a faixa etária foi um dado fornecido por apenas 13 das mulheres entrevistadas, a média de idade foi de 26 anos e as idades variaram no intervalo de 20 a 33 anos. Em relação a quantidade de filhos: 13 mulheres tinham 1 filho; 21 mulheres tinham 2 filhos; 10 mulheres tinham 3 filhos; 2 mulheres tinham 4 filhos; e 4 mulheres não informaram a quantidade total de filhos que possuíam. Sobre a idade das crianças com doenças falciformes: 9 mulheres tinham crianças com até um ano de idade; 12 mulheres com crianças de 1 ano até 2 anos de idade; 8 mulheres com crianças de 2 anos até 3 anos de idade; 9 mulheres com crianças de 3 anos ou mais de idade; e 12 mulheres não informaram a idade dos filhos. Não foram coletados dados sobre grau de instrução, renda das participantes e estado civil. Todas as entrevistadas residiam em regiões periféricas ou do entorno do Distrito federal, como foi possível observar por ocasião das entrevistas em domicílio ou nos relatos das entrevistas feitas no hospital.

\section{Resultados e discussão}

A pesquisa mostrou que a noção de risco reprodutivo e de planejamento familiar das mulheres não se pauta somente pelas informações recebidas por ocasião das sessões de aconselhamento genético que integram a triagem neonatal. Um fator decisivo na interpretação do risco reprodutivo reside na experiência do cuidado da criança com doença falciforme e no contexto social onde as mulheres estão inseridas. Nesse sentido, tendo como ponto de partida a noção de risco reprodutivo adotada pelas mulheres, a pesquisa revelou as seguintes percepções no campo das decisões reprodutivas entre as participantes: 1 . mulheres cuja decisão é a de não mais ter filhos; 2. mulheres que pretendem ter outros filhos; e 3. mulheres cujo projeto reprodutivo futuro ainda está sendo elaborado com base nas informações recebidas no programa de triagem. As noções de risco reprodutivo das mulheres estão diretamente relacionadas às posições adotadas em relação ao planejamento familiar.

\section{"Não quero ter filhos mais não"}

O risco reprodutivo de ter uma criança com anemia falciforme costuma ser exageradamente dimensionado por mulheres que informaram não pretender ter outros filhos. Esse fato pode ser considerado um meio adotado por elas a fim de convencerem familiares e amigos de que as chances elevadas de nascimento de outra criança com essa doença justificariam a decisão tomada no campo reprodutivo. Os seguintes relatos mostram a dimensão dada ao risco diante da possibilidade de outra gestação quando mulheres que já têm uma criança com essa enfermidade afirmaram optar por não ter outras:

A médica disse que era $100 \%$ de chance de ter ou de não ter [outro filho com a doença]. (mulher, idade não informada, mãe de criança com 9 meses de idade)

Eles [profissionais de saúde] lá é que falam, porque a chance de nascer com anemia falciforme é noventa por cento dos casos. É raro nascer um sim e um não, provavelmente não pode. Até porque vai nascer com o mesmo problema... eu decidi por causa disso, pois eu sei que vai nascer com o mesmo problema, pois sempre nasce, é raro nascer um com anemia e outro não, sempre nasce com anemia. (mulher, idade não informada, mãe de criança com 2 anos de idade)

Algumas mulheres sugerem que o risco reprodutivo elevado de uma segunda gestação re- 
sultar no nascimento de outra criança com doença falciforme teria sido uma informação enfatizada por profissionais de saúde:

[...] a médica falou que se eu tiver outro filho, também pode nascer com a doença falciforme. Então, como eu já não queria ter outro filho e ela me alertando sobre isso, aí eu não quero (mulher, 27 anos, mãe de criança com 1 ano de idade).

Entretanto, essa não costuma ser uma informação presente nas sessões de aconselhamento genético fornecidas a pais de crianças com doenças falciformes no hospital pesquisado, como mostrou um estudo observacional lá realizado ${ }^{27}$. Durante o aconselhamento genético naquele hospital os pais, geralmente ambos com o traço falciforme, são informados sobre o que é a doença, as possíveis manifestações clínicas e a origem hereditária ${ }^{27}$. As profissionais do aconselhamento genético costumavam utilizar fichas ilustrativas e informar corretamente as diferentes probabilidades de nascimento de outras crianças com anemia falciforme, segundo a identidade genética dos pais $^{27}$. O uso de fichas ilustrativas ou mesmo de metáforas é uma prática comum em sessões de aconselhamento genético para tornar a informação mais inteligível ${ }^{28}$.

A tendência de superestimar o risco reprodutivo encontrada neste estudo também foi uma constatação feita por outros pesquisadores do campo da genética ${ }^{11,12}$, e decorre da experiência das mulheres, dos valores culturais e de fatores psicológicos e ambientais ${ }^{11,15,29}$. Como resultado da combinação desses elementos, a noção de risco apresenta uma lógica própria que não está fundamentada só na racionalidade biomédica, mas é baseada principalmente na experiência do cuidado das crianças com doença falciforme e dos contextos onde as mulheres estão inseridas. O cuidado da criança com doenças falciformes, em especial a anemia falciforme, envolve todas as ações adotadas para tratar a doença, como uso de medicamentos, dieta adequada, uso de roupas apropriadas e outros procedimentos indispensáveis à redução da morbidade.

A pesquisadora Rayna Rapp mostra que a noção de risco é construída com base em fundamentos quantitativos e qualitativos relacionados a determinada doença ou característica genética identificada nos exames ${ }^{28,30}$. Para interpretar o diagnóstico apresentado e fazer escolhas reprodutivas, as mulheres combinam às evidências produzidas pelos resultados do teste genético a sua percepção pessoal da informação sobre a doença. A percepção pessoal sobre esta e suas implicações reprodutivas é bastante influenciada pela trajetória de vida, contexto social, crenças, valores e condições socioeconômicas das mulheres e sua estrutura familiar ${ }^{28,31}$. Nesse sentido, a superestimação do risco reprodutivo pode ser considerada tanto um modo de justificar a decisão reprodutiva diante das reduzidas opções, como um desdobramento da dificuldade de compreender a explicação médica sobre as propriedades hereditárias da doença.

As opções reprodutivas disponíveis às mulheres com chances de gerarem filhos com doenças genéticas são reduzidas no Brasil. A principal diferença em relação a outros países, como os Estados Unidos, está relacionada à possibilidade de interrupção da gravidez. Caso descubram precocemente a existência de doença genética no feto, por meio de testes diagnósticos como a amniocentese, as mulheres brasileiras não poderão interromper a gravidez em virtude da legislação proibitiva para o aborto ${ }^{28,31}$.

A falta de acesso às novas tecnologias reprodutivas é outro fator que restringe as opções das mulheres brasileiras nesse campo. A seleção de embriões seria uma das tecnologias médicas capazes de evitar o nascimento de crianças com doenças genéticas, mas essa tecnologia ainda não é ofertada. Aquelas submetidas ao aconselhamento genético e dependentes do sistema público de saúde só têm uma forma de controlar o nascimento de outros filhos com doença falciforme: a opção pela não reprodução. $\mathrm{O}$ acesso às tecnologias reprodutivas e a outros recursos médicos é diferenciado no caso das mulheres da elite brasileira e, portanto, os mesmos dilemas reprodutivos poderiam ter repercussões distintas em quem tiver elevado poder aquisitivo ${ }^{32}$.

A outra hipótese que poderia ser considerada para explicar a superestimação do risco reprodutivo é a de que a informação probabilística presente na retórica explicativa dos profissionais de saúde sobre a doença falciforme é de difícil compreensão e, consequentemente, provocaria interpretações diversas. Uma pesquisa realizada entre pessoas com diferentes níveis de escolaridade mostrou que a informação genética envolvendo probabilidades da doença falciforme é de difícil compreensão mesmo para quem possui elevado grau de instrução ${ }^{33}$. No presente estudo, entretanto, algumas das percentagens apresentadas pelas mulheres, como as chances de noventa ou de cem por cento do nascimento de crianças com essa enfermidade, sugerem que o risco reprodutivo pode ter sido intencionalmente superestimado, visto que tais chances não ocorrem entre casais em que ambos possuem o traço 
falciforme e, por outro lado, as entrevistadas que informaram essas chances superestimadas são as mesmas que declararam a decisão de não mais ter filhos.

A existência de um parente próximo com a doença, no caso os filhos ou mesmo outros parentes, pode ser outro fator que explicaria o modo como o risco reprodutivo de ter outras crianças com doença falciforme foi mensurado por uma parcela das mulheres:

[...] tem que usar o acompanhamento para evitar [gravidez de uma criança com anemia falciforme]... meu esposo, na família dele, já tem um sobrinho [com a doença falciforme] (mulher, idade não informada e mãe de criança com 3 anos de idade).

Um estudo qualitativo sobre concepções de risco e doenças hereditárias mostrou que a percepção do risco é influenciada pela quantidade de casos e pela relação de parentesco com as pessoas afetadas pelas doenças em uma mesma família $^{13}$. As participantes da pesquisa estavam em relação direta com as crianças com doença falciforme, pois eram as mães e exerciam o papel de cuidadoras. Em alguns casos, informaram que as avós também compartilhavam o papel de cuidadoras. O grau de parentesco e a experiência do cuidado são dois fatores que contribuiriam, portanto, para a compreensão de como o risco reprodutivo de ter outros filhos com doença falciforme foi percebido pelas mulheres.

As mulheres também apontaram outras razões para justificar a decisão de não ter mais filhos. O tamanho da família e as exigências envolvidas no cuidado de uma criança com doença falciforme foram as mais frequentes. Muitas, afirmaram possuir uma família cujo tamanho estaria adequado, pois já teriam a quantidade de filhos desejada:

[...] três filhos já está bom, meu mais velho já está com quatorze anos (mulher, 33 anos, mãe de criança com 4 anos de idade);

[...] não, eu já não queria mesmo mais filhos, porque eu já tenho duas... (mulher, 33 anos, mãe de criança com 9 meses de idade).

O tamanho da família também foi uma das razões que influenciaram as decisões reprodutivas de mães de crianças com anemia falciforme nos Estados Unidos, como mostrou uma pesquisa sociológica em famílias de baixa renda ${ }^{22}$.

As exigências representadas pela experiência do cuidado de uma criança com doença falciforme foi outro desafio apontado por uma parcela das mulheres entrevistadas para justificar a decisão de não mais ter filhos:
... a alimentação dela tem de ser com muita verdura, então, não penso em ter outros filhos ... (mulher, idade não informada, mãe de criança com 2 anos de idade).

Segundo o relato das mulheres, ter uma segunda criança com doença falciforme envolveria a necessidade de ampliação da renda familiar para a adoção dos cuidados prescritos, como a compra de alimentos adequados, a aquisição de medicamentos e as visitas periódicas ao médico. O tratamento e o acompanhamento diário das crianças, um papel atribuído às mulheres, também foi apontado como um fator que contribuiria para a decisão de não ter mais filhos. Algumas das entrevistadas afirmaram ter deixado temporariamente o mundo do trabalho para se dedicarem exclusivamente aos cuidados da criança, principalmente nos primeiros anos de vida. Uma parcela das que suspenderam suas atividades laborais para exercerem o papel de cuidadoras informou também que enxergava no crescimento dos filhos uma possibilidade de retornar ao mundo do trabalho, o que fortaleceria até mesmo a renda familiar e ampliaria os recursos disponíveis para o tratamento da doença.

As mulheres expressaram ainda o receio de um segundo filho com anemia falciforme ter manifestações mais graves, tendo em vista a variabilidade clínica da doença:

[...] eu tenho medo de se eu inventar de ter outro e vier com essa doença e for daqueles meninos que fica só doente o tempo todo... (mulher, idade não informada, mãe de criança com 1 ano de idade).

Dessa forma, as responsabilidades envolvidas nos cuidados de uma criança com anemia falciforme, a impossibilidade de prever as manifestações clínicas da doença, caso estivesse presente em um segundo filho, e o desejo da cuidadora de retomar a posição que ocupava no mundo do trabalho foram fatores identificados como de importância para as escolhas feitas no campo reprodutivo.

A decisão de não ter mais filhos adotada como estratégia para evitar uma doença genética é um tema que tem gerado debates e revelado posições diversas ${ }^{28,31,34,35}$. Seria essa uma atitude eugênica e discriminatória em relação às pessoas com deficiência? A resposta para essa pergunta está diretamente relacionada às motivações da mulher que decidiu não mais se reproduzir e das circunstancias nas quais a decisão foi tomada. Segundo Jonathan Glover, as mulheres podem decidir não ter filhos com deficiência e essa não ser considerada uma escolha discriminatória ou 
eugênica ${ }^{31}$. O desafio está em analisar as racionalidades que fundamentam as escolhas reprodutivas antes de fazer um julgamento moral das mulheres. Este estudo revelou que as mulheres cuja decisão foi a de não mais ter filhos fundamentaram essa escolha em virtude dos recursos já envolvidos no cuidado de uma criança com a doença e das próprias limitações socioeconômicas ou as de sua da família em receber um segundo filho que exigirá cuidados semelhantes, a depender da imprevisível manifestação clínica da doença falciforme.

\section{"Eu pretendo ter outro filho"}

Um segundo grupo identificado na pesquisa é composto pelas mães que desejam ter outros filhos, independente da possibilidade de recorrência da doença falciforme. Uma característica observada foi que as entrevistadas conheciam as chances estatísticas corretas de ter outra criança com a enfermidade e não apontaram essa possibilidade como um empecilho diante da vontade de ter outros filhos. Os seguintes relatos mostram essa vontade, independente da possibilidade da reincidência na família:

[...] eu pretendo ter outro filho. Porque eu acho um filho pouco, tenho vontade de ter outro. Pode [nascer com anemia falciforme], $25 \%$ de chances. (mulher, idade não revelada e mãe de criança com idade também não mencionada)

[...] eu vejo como uma possibilidade futura estar em situação melhor e ter outra criança ... a gente já trata de um e já conhece o pessoal [do hospital]. Tratar o resto [outros possíveis filhos com anemia falciforme] é normal. Se outro menino nascer com doença falciforme, vamos para o hospital do mesmo modo. Com a mesma satisfação que a gente leva um, leva os [filhos] mais distantes. (mulher, 22 anos, mãe de criança com 6 anos de idade)

Embora haja o reconhecimento da possibilidade de recorrência da doença, esse risco reprodutivo tem seu impacto diminuído diante do atendimento médico fornecido e da vontade de expandir o tamanho da família. O diagnóstico e o tratamento precoces assegurados pelos programas de triagem neonatal e o cuidado cotidiano já oferecido a uma criança com doença falciforme contribuem para que o risco reprodutivo seja redimensionado simbolicamente. A doença não seria, dessa forma, algo restrito ao corpo biológico, mas também diretamente influenciado pelo meio onde se vive e os recursos disponívei ${ }^{34,36}$. Desde que o meio social ofereça condições para o desenvolvimento de uma criança com doença falcifor- me ou mesmo que a "situação" familiar seja capaz de atender às especificidades da criança, como sugere um dos relatos acima, a possibilidade de outros filhos doentes é reelaborada pelas mulheres. A doença falciforme recebe outros significados para além daqueles difundidos na narrativa de profissionais e instituições da saúde, que é fundamentada, principalmente, na descrição biológica da doença e suas repercussões clínicas.

A doença falciforme é vista por esse grupo de mulheres como uma doença crônica e passível de tratamento. Nesse sentido, os prognósticos de morbidade e mortalidade comumente associados são criticamente avaliados pelas mulheres com base na experiência de ter e cuidar de uma criança com a enfermidade. Sua gravidade e a ausência de cura, informações destacadas no discurso biomédico, adquirem um novo significado para as cuidadoras que têm a experiência como uma fonte adicional de informações para decisões no campo reprodutivo. Algumas pesquisas realizadas nos Estados Unidos também mostraram que o diagnóstico precoce ou mesmo a descoberta de um filho com doença falciforme não exerciam grandes impactos nas escolhas reprodutivas das mulheres ${ }^{22,28}$.

O tamanho da família e a idade dos pais também são fatores que justificam o desejo de ter novos filhos. As mulheres com apenas um filho, em geral, informaram o desejo de expandir a família. A chegada de outro, entretanto, foi apontada como um evento a ser planejado tendo em vista os cuidados que uma criança com doença falciforme exige nos primeiros anos de vida:

[...] eu pretendo ter [outro filho] quando ele [criança com anemia falciforme] estiver maior. Porque aí ele já está grandinho, ele já sabe cuidar mais, aí eu pretendo ter outro (mulher, idade não informada, mãe de criança com 2 anos).

As mulheres reconhecem a possibilidade do nascimento de outra criança com doença falciforme e, nesse sentido, um intervalo de tempo até a próxima gravidez é uma estratégia necessária para que o primeiro filho atinja a idade na qual é capaz de desenvolver o autocuidado, o que viabiliza o desejo da mãe de ter outro. $\mathrm{O}$ autocuidado se baseia em um conjunto de práticas adotadas para identificar, prevenir e/ou tratar, sob orientação dos profissionais de saúde, as manifestações clínicas da doença no decorrer da vida ${ }^{37}$.

A mudança de companheiro também foi apontada como um dos fatores que motivavam a decisão de ter outros filhos. Considerando o genótipo diferenciado de um novo parceiro que não possuiria o traço ou a doença falciforme, as 
mulheres enxergavam a possibilidade de reduzir ou mesmo impedir o risco de nascimento de outra criança com a enfermidade. Uma das entrevistadas, grávida novamente e com um novo par, expressou sua expectativa da seguinte forma:

[...] ele [novo companheiro] pergunta se tem ou se corre o risco desse [atual gravidez] nascer também com anemia falciforme. Falei que não. A não ser que ele [novo companheiro] tivesse o traço [falciforme] também (mulher, 23 anos, mãe de criança com 3 anos de idade).

A associação entre troca de parceiros e diminuição do risco de nascimento de crianças com doenças falciformes também foi constatada em outras pesquisas sobre escolhas reprodutivas ${ }^{15,22}$. As mulheres, embora reconheçam que têm o traço, apostam na possibilidade de um novo companheiro possuir um genótipo sem sua presença. Esses novos arranjos familiares, surgiriam, assim, como um meio de evitar novos casos da enfermidade.

O acesso a testes diagnósticos adicionais é outro recurso que poderia ser empregado na assistência a mulheres que decidem ter outros filhos. O de amniocentese permitiria descobrir se o seguinte terá a doença e antecipar cuidados em saúde ou planejar arranjos familiares para a chegada da criança. Rapp mostrou em sua pesquisa sobre amniocentese que mesmo aquelas contrárias ao aborto optavam pela realização do teste como um meio de antecipar cuidados em saúde a serem dispensados à criança que iria nascer ${ }^{28}$. Os testes diagnósticos têm esse poder de antecipar informações e verdades sobre os corpos e possibilitam a tomada de decisões reprodutivas ainda que em contextos cujas opções sejam restritas, como no Brasil. Entretanto, esses testes envolvem também repercussões físicas e psicológicas nelas, o que exige um cuidadoso planejamento do modo como serão empregados e da assistência no decorrer do processo de exames ${ }^{28,35}$.

\section{"Eu não sei"}

O terceiro grupo de mulheres é composto por aquelas cuja decisão reprodutiva com relação a outros filhos ainda não foi tomada. Elas entendem corretamente o risco de gerar outros indivíduos com a doença e, diante dessa possibilidade, se sentem indecisas. Os relatos sugerem que elas investem em um processo de negociação com os companheiros no sentido de compartilhar opiniões e a responsabilidade de uma decisão futura:

Ele [companheiro] disse que quer outra menina, mas eu não sei, não. Sei lá, eu tenho medo... eu não queria mais não, mas ele disse que quer uma menina (mulher, idade não revelada, mãe de criança com 2 anos de idade).

... O pai [da criança] pretende [ter outros filhos], eu não sei se eu quero mais, não (mulher, idade não revelada, mãe de criança com 10 meses de idade).

As mulheres que afirmam estar indecisas com relação a um segundo filho atrelam essa indecisão à opinião dos companheiros. Em geral, elas já têm uma opinião formada sobre o que representaria o nascimento de outra criança com doença falciforme e os cuidados exigidos. Entretanto, a expectativa do parceiro com um novo filho ou mesmo o receio de a decisão tomada afetar a relação conjugal passam a ser um dilema que dificulta o diálogo sobre a possibilidade de uma nova gravidez. Ao mesmo tempo em que reconhecem o valor social atribuído ao papel da maternidade, sabem as responsabilidades que seu exercício exige quando se tem uma criança com essa enfermidade. Dessa forma, a possibilidade de uma futura gestação passa a ser objeto de negociação do casal, tendo em vista as implicações que o cuidado de outra criança poderá representar na vida delas e da família. A anemia falciforme foi reconhecida como um tipo cujas manifestações clínicas podem ser mais intensas.

O contexto social onde as mulheres estão inseridas também pode suscitar questionamentos sobre a quantidade de filhos do casal e contribuir para a indecisão com relação à segunda gravidez. Nesse sentido, surge um dilema entre optar por não ter mais filhos em virtude de o que representaria outra criança com doença falciforme na família e atender à "ideologia da maternidade"22. Uma das entrevistadas expressou da seguinte forma a pressão sofrida pelo meio social:

[...] a sociedade trata como pessoas doentes porque a mulher não quer ter outros filhos... (mulher, idade não informada, mãe de criança com 2 anos de idade).

Portanto, é possível inferir que, em alguns casos, a suposta indecisão expressa por algumas mulheres seria um meio de ocultar uma decisão reprodutiva já tomada e mantida em sigilo para evitar ou adiar julgamentos morais tanto do companheiro quanto de familiares e amigos diante de escolhas consideradas controversas. Elas filtram o recebimento da informação genética com base na sua história de vida e nas informações recebidas nas instituições de saúde. As decisões reprodutivas refletem um mosaico de saberes que a mulher combina às aspirações de vida para si e para o futuro da criança ${ }^{28}$. 
Algumas informaram que, mesmo diante da expectativa dos companheiros, não hesitaram em negociar a vinda de um segundo filho. Nesses casos, as mulheres se revestem da autoridade que possuem, uma vez que desempenham o papel de cuidadoras, e passam a ponderar com os companheiros as possíveis implicações:

[...] ele queria ter outro, sim, porque como é o primeiro dele e ele é novo, mas aí eu conversei com ele. Ai ele falou assim, 'está certa, a gente tem que evitar mesmo porque futuramente a gente vai querer trabalhar, os dois juntos, para ter as nossas coisas, e se vier uma criança vai atrapalhar tudo...' (mulher, idade não revelada, mãe de criança com 1 ano de idade).

A negociação empreendida pelas mulheres e a suposta indecisão podem ser consideradas estratégias empregadas para expressar e garantir a preservação de escolhas reprodutivas contrárias às expectativas do companheiro, de familiares ou da comunidade onde se vive.

\section{Considerações finais}

A pesquisa mostrou que as noções de risco reprodutivo adotadas pelas mulheres participantes das sessões de aconselhamento genético do programa de triagem neonatal não são construídas somente com base na informação biomédica sobre a doença e suas repercussões na rotina familiar, como a adoção de tratamentos e de cuidados preventivos. É da combinação entre esta, as experiências pessoais e as perspectivas de vida para si e para os filhos que constroem a noção de risco reprodutivo e fundamentam suas escolhas no campo do planejamento familiar. Consequentemente, algumas optam por ter outros filhos e outras preferem aguardar para a tomada de decisão, ou mesmo decidem não mais se reproduzir.

Ao construírem a noção de risco reprodutivo e tomarem decisões, as mulheres adotam discursos destinados à preservação das escolhas. Os relatos sugerem que algumas mantêm uma estratégia discursiva amparada na medicalização das escolhas reprodutivas. Por exemplo, uma parcela delas afirmou que não mais teria filhos em virtude de ter sido submetida à cirurgia da ligadura de trompas ou de o companheiro ter feito vasectomia. As cirurgias de esterilização seriam, portanto, um impedimento à reprodução socialmente valorada. Para outras, a morbidade representada pela doença que afeta a criança seria um alerta médico ou quase uma prescrição no sentido de prevenir a vinda de outros filhos. Esse fenômeno de devolver para a instituição médica a responsabilidade moral por escolhas reprodutivas que poderiam ser alvo de questionamentos no microcosmo onde se vive foi observado em alguns dos relatos e pode ser objeto de pesquisas futuras.

Foi possível observar também a construção de novas narrativas em torno de o que é uma vida com doença falciforme. As mulheres cuja decisão é a de ter outros filhos a consideravam tratável e que permite às crianças se desenvolverem, desde que possuam os recursos materiais e afetivos necessários. Essa percepção sobre a doença falciforme pode ser considerada um dos resultados trazidos pelo programa de triagem neonatal, que, ao fornecer diagnóstico e tratamento precoces, reduz a morbimortalidade da doença e potencializa cada vez mais a qualidade e a expectativa de vida. A anemia falciforme começa a ser enxergada como uma doença crônica em que o meio social influenciará em larga medida a trajetória de vida das crianças.

Finalmente, o processo de revisão da literatura brasileira mostrou a escassez de publicações sobre mulheres cuidadoras, reprodução e doença falciforme. Em especial são necessários estudos sobre o perfil socioeconômico e inserção das mulheres cuidadoras de crianças com doenças falciformes no mercado de trabalho, essa é uma lacuna presente neste estudo e um dado importante para entender aspectos relacionados às escolhas reprodutivas. No cenário internacional, também são poucos os estudos, e geralmente os pesquisadores que abordam esse tópico se voltam para análises em torno de doenças específicas, como câncer de mama, fibrose cística ou doença de Huntington ${ }^{11}$. A questão do risco reprodutivo associado à doença falciforme está à margem das discussões na literatura, apesar da centralidade epidemiológica, ética e social da doença. 


\section{Referências}

1. Souza C, Schwartz I, Giugliani R. Triagem neonatal de distúrbios metabólicos. Cien Saude Colet 2002; 7(1):129-137.

2. Ofori-Acquah S, Ohene-Frempong K. Beyond national borders: a global perspective on advances in sickle cell disease research and management, and new challenges in the Genome Era. In: Pace B, editor. Renaissance of sickle cell disease research in the Genome Era. London: Imperial College Press; 2007. p. 333-345.

3. Carvalho T. Triagem neonatal no Brasil. Rev. Médica de Minas Gerais 2005; 15:20-22.

4. Botler J, Camacho L, Cruz M, George P. Triagem neonatal - o desafio de uma cobertura universal e efetiva. Cien Saude Colet 2010; 15(2):493-508.

5. Rodrigues C, Araújo I, Melo L. A família da criança com doença falciforme e a equipe de enfermagem: revisão crítica. Rev Bras Hematol Hemoter 2010; 32(3):257-264.

6. Corrêa M, Guilam M. O discurso do risco e o aconselhamento genético pré-natal. Cad Saude Publica 2006; 22(10):2141-2149.

7. Ramalho A, Magna L, Paiva e Silva R. A portaria n. 822/01 do Ministério da Saúde e as peculiaridades das hemoglobinopatias em saúde pública no Brasil. Cad Saude Publica 2003; 19(4):1195-1199.

8. Guedes C. O campo da anemia falciforme e a informação genética: um estudo sobre o aconselhamento genético [dissertação]. Brasília: Universidade de Brasília; 2006.

9. Pina-Neto J. Aconselhamento genético. J Pediatr 2008; 84(4):S20-S26.

10. Guedes C, Diniz D. A ética na história do aconselhamento genético: um desafio à educação médica. Rev Bras Educ Medic 2009; 33(2):247-252.

11. Sivell S, Elwyn G, Gaff C, Clarke A, Iredale R, Shaw C. How risk is perceived, constructed and interpreted by clients in clinical genetics, and the effects on decision making: systematic review. J Genet Couns 2008; 17(1):30-63.

12. Scott S, Prior L, Wood F, Gray J. Repositioning the patient: the implications of being 'at risk'. Soc Sci Med 2005; 60(8):1869-1879.

13. Sanders T, Campbell R, Donovan J, Sharp D. Narrative accounts of hereditary risk: knowledge about family history, lay theories of disease, and "internal" and "external" causation. Qual Health Res 2007; 17(4):510-520.

14. Atkin K, Ahmed S, Hewison J, Green J. Decisionmaking and ante-natal screening for sickle cell and thalassaemia disorders. Curr Sociol 2008; 56(1):7798.

15. Gallo A, Wilkie D, Suarez M, Labotka R, Molokie R, Thompson A, Hershberger P, Johnson B. Reproductive decisions in people with sickle cell disease or sickle cell trait. West J Nurs Res 2010; 32(8):10731090.

16. Laguardia J. No fio da navalha: anemia falciforme, raça e as implicações no cuidado à saúde. Estud Fem 2006; 14(1):243-262.
17. Bitarães E, Oliveira B, Viana M. Adesão à antiobioticoterapia profilática em crianças com anemia falciforme: um estudo prospectivo. J Pediatr 2008; $84(4): 316-322$

18. Diniz D, Guedes C, Barbosa L, Tauil P, Magalhães I. Prevalência do traço e da anemia falciforme em recém-nascidos do Distrito Federal, Brasil, 2004 a 2006. Cad Saude Publica 2009; 25(1):188-194.

19. Guimarães T, Miranda W, Tavares M. O cotidiano das famílias de crianças e adolescentes portadores de anemia falciforme. Rev Bras Hematol Hemoter 2009; 31(1):9-14

20. Felix A, Souza H, Ribeiro S. Aspectos epidemiológicos e sociais da doença falciforme. Rev Bras Hematol Hemoter 2010; 32(3):203-208.

21. Abreu I, Braguini W. Triagem neonatal: o conhecimento materno em uma maternidade no interior do Paraná, Brasil. Rev Gaúcha Enferm 2011; 32(3): 596-601.

22. Hill S. Managing sickle cell disease in low-income families. Philadelphia: Temple University Press; 1994.

23. Dyson S. Ethnicity and screening for sickle cell/thalassaemia: lessons for practice from the voices of experience. London: Elsevier; 2005.

24. Rouse C. Uncertain suffering: racial health care disparities and sickle cell disease. California: University of California Press; 2009.

25. Gaskell G. Entrevistas individuais e grupais. In: Bauer M, Gaskell G, organizadores. Pesquisa qualitativa com texto, imagem e som: um manual prático. Petrópolis: Vozes; 2004. p. 64-89.

26. Strauss A, Corbin J. Pesquisa qualitativa: técnicas e procedimentos para o desenvolvimento de teoria fundamentada. Porto Alegre: Artmed, Bookman; 2008.

27. Guedes C. Anemia falciforme e triagem neonatal: o significado da prevenção para as mulheres cuidadoras [tese]. Brasília: Universidade de Brasília; 2009.

28. Rapp R. Testing women, testing the fetus: the social impact of amniocentesis in America. New York: Routledge; 2000.

29. Ahmed S, Atkin K, Hewison J, Green J. The influence of faith and religion and the role of religious and community leaders in prenatal decisions for sickle cell disorders and thalassaemia major. Prenat Diagn 2006; 26(9):801-809.

30. Rapp R. Chromosomes and communication: the discourse of genetic counseling. Med Anthropol Q 1988; 2(2):143-157.

31. Glover J. Choosing children: genes, disability, and design. Oxford: Oxford University Press; 2006.

32. Chazan L. O aparelho é como um automóvel; a pista é a paciente. Para além do ensino de tecnologia no pré-natal. Physis 2011; 21(2):601-627.

33. Diniz D, Guedes C, Trivelino A. Educação para a genética e saúde pública: um estudo de caso sobre a anemia falciforme. Cien Saude Colet 2005; 10(2):365372. 
34. Asch A. Diagnóstico pré-natal e aborto seletivo: um desafio à prática e às políticas. Physis 2003 13(2):287-320.

35. Green R. Babies by design: the ethics of genetic choice. New Haven, London: Yale University Press; 2007.

36. Beck U. Sobre a incompreendida falta de experiência da genética humana e as consequências sociais do não-saber relativo. In: Boni L, Jacob G, Salzano F, organizadores. Ética e genética. Porto Alegre: Editora PUC-RS; 1998. p. 39-62.

37. Araujo P. O auto cuidado na doença falciforme. Rev Bras Hematol Hemoter 2007; 29(3):239-246.

Apresentado em 15/06/2011

Aprovado em 11/02/2012

Versão final apresentada em 06/04/2012 